(Johnson et al., 1969). This is a further demonstration of the biochemical consequences of imbalance between levels of emotional and physical activity. It provides some additional encouragement for those investigating the place of "exercise therapy" in the prevention and treatment of cardiovascular disease.

In addition, this study indicates that sudden exposure to intense heat, as in sauna baths, Turkish baths, and presumably the "coffee baths" becoming fashionable in Japan, may contain an element of risk in those prone to coronary insufficiency. This group includes a number of middle-aged men with tiredness, lethargy, and "fibrositis" in the chest and shoulder who will seek out the most gruelling of these artificial environments and stay in longest to "sweat it out of their system." Apart from descriptions such as "my heart was thumping" and "I thought my heart was going to stop" appearing in recent articles on the subject (Observer, 1971), sudden syncopal attacks just on standing to leave the sauna are not uncommon.

If any recommendations can be made on the basis of the limited number of subjects in this study perhaps a cautious approach for the middle-aged and elderly sauna novice might be indicated. The cooler, lower levels away from the heater should be tried in the high temperature saunas being promoted in Britain with a time limit of five minutes. However, at the lower temperature of $60-70^{\circ} \mathrm{C}$ more common in Finnish saunas, Eisalo's (1956) work has shown that a more leisurely approach can be used without apparently undue strain on the cardiovascular system. The recumbent posture customary in these Finnish saunas also helps adequate coronary artery perfusion, rather than sitting or standing in the smaller units found in Britain. For many healthy people the sense of relaxation and wellbeing induced by a sauna will continue to outweigh the potential dangers of the circulatory gymnastics involved. On the basis of these experiments, however, it appears to be neither healthgiving nor heroic to prolong a sauna bath past the point where a person feels he has had enough.

\section{References}

Carlson, L. A., and Oro, L. (1965). fournal of Atherosclerosis Research, 5, 436. Carruthers, M. E. (1969). Lancet, 2, 1170.

Carruthers, M., Taggart, P., Conway, N., Bates, D., and Somerville, W. (1970). Lancet, 2, 62.

Carruthers, M. (1972). In Automation in Analytical Chemistry, ed. L. T. Skeggs. London. In press.

Eisalo, A. (1956). Annales Medicinae Experimentalis et Biologiae Fenniae, 34, Suppl. No. 4.

Hanson, J. S., Tabakin, B. S., and Levy, A. M. (1966). British Heart fournal, 28, 557.

Johnson, R. H., Walton, J. L., Krebs, H. A., and Williamson, D. H. (1969). Lancet, 2, 1383.

Jurand, J., and Oliver, M. F. (1970). Atherosclerosis, 11, 157.

Kurien, V. A., Yates, P. A., and Oliver, M. F. (1971). European fournal of Clinical Investigation, 1, 225.

Lachman, A. B., Semler, H. J., and Gustafson, R. H. (1965). Circulation, 31, 557 .

Lepeschkin, E., et al. (1960). American fournal of Cardiology, 5, 594

Mitchell, J. H., and Shapiro, A. P. (1954). American Heart fournal, 48, 323.

Observer, 1971, Review, 3 October.

Ott, V. T. (1948). Die Sauna. Basel, Schwabe. Quoted by Eisalo (1956)

Page, L. B., Raker, J. W., and Berberick, F. R. (1969). American fournal of Medicine, 47, 648 .

Rasanen, M. A. (1951). Duodecim, 67, Suppl. No. 21. Quoted by Eisalo (1956).

Sherif, N. E., Shahwan, L., and Sorour, A. H. (1970). American Heart Fournal, 79, 305

Sodi Polares, D., Medrano, G. A., Bisteni, A., and Ponce de Leon, J. J. (1971). Deductive and Polyparametric Electrocardiography. Ed. Instituto Nacional de Cardiologia de Mexico.

Somerville, W., Taggart, P., and Carruthers, M. (1971). British Heart fournal, 33, 608.

Taggart, P., Gibbons, D., and Somerville, W. (1969). British Medical fournal, 4, 130 .'

Taggart, P., and Carruthers, M. (1971). Lancet, 1, 363.

Vendsalu, A. (1960). Acta Physiologica Scandinavica, 49, Suppl. No 173.

Wenke, M. (1966). In Advances in Lipid Research, ed. R. Paoletti and D. Kritchevsky, vol. 4, p. 69. London, Academic press.

\title{
Continuous Recording of Direct Arterial Pressure and Electrocardiogram in Unrestricted Man
}

\author{
W. A. LITTLER, A. J. HONOUR, P. SLEIGHT, F. D. STOTT
}

British Medical fournal, 1972, 3, 76-78

\section{Summary}

A system has been devised which records direct arterial pressure, electrocardiogram, and other variables in man with no restriction of activity. The advantage of this system is that the record is on magnetic tape, and it is possible to replay the records at various speeds to analyse each beat or to produce an entire 24-hour record on a few feet of paper. A marker allows the timing of relevant events. Initial experience with this procedure indicates that is is safe and reliable.

\section{Introduction}

Automatic sphygmomanometers operating at intervals can approach the ideal of continuous recording of arterial pressure, but the apparatus is bulky and the information gained, though

\section{Radclifie Infirmary, Oxford}

W. A. LITTLER, M.D., M.R.C.P., Lecturer, Cardiac Department A. J. HONOUR, M.A., D.PHIL., First Assistant, Department of the Regius Professor of Medicine

P. SLEIGHT, M.D., F.R.C.P., Consultant, Cardiac Department

M.R.C. Clinical Research Centre, Northwick Park, Middlesex F. D. STOTT, M.A., D.PHI., Member of Scientific Staff valuable, is incomplete (Richardson et al., 1964). A small, completely portable apparatus was therefore developed which permitted continuous direct recording of both systolic and diastolic pressures over periods of up to 24 hours, the movements of the subject being entirely unrestricted with no observer present except to service the apparatus every 12 hours (Bevan et al., 1969). The pressures measured with this original apparatus were recorded on 1 in $(2.5 \mathrm{~cm})$ bromide paper moving at 6 in $(15 \mathrm{~cm})$ an hour, and its small size made it necessary to use an episcope to enlarge the trace between five and six times, as the arterial pressures had to be read directly from the record, which was viewed through a calibration grid. This made the analysis of the record tedious and time-consuming and, because of the slow paper speed, made resolution of individual beats impossible, and much information, particularly of short-lived events, could not be resolved.

Further development of this apparatus has been made which overcomes the deficiencies of the photographic record. By using a miniature analogue multichannel tape recorder electrical signals representing systolic and diastolic pressures, electrocardiogram, event marker, and other values are impressed on magnetic tape. A playback deck enables the signals to be displayed simultaneously on an oscilloscope or to be converted to a permanent record by using a Consolidated Electrodynamics (5-127) (UV) recorder.

In conjunction with the Atomic Energy Research Establishment, Harwell, ancillary electronic equipment (Harwell 6000 
series B.P. Analyser 3621) has also been developed whereby in about one hour it is possible to produce an automatic analysis of the whole 24-hour study for systolic, diastolic, mean and pulse pressures, and pulse interval.

\section{Apparatus}

This consists basically of three units, a perfusion pump, transducer, and miniature analogue tape recorder. The perfusion pump is as previously described (Bevan et al., 1969), but the strain-gauge type of transducer has been replaced by a capacitance manometer which is more robust, of smaller volume displacement, about $0.01 \mathrm{~mm}^{3} / 100 \mathrm{~mm} \mathrm{Hg}$, and over a range of $300 \mathrm{~mm} \mathrm{Hg}$ has greater linearity of response.

The recording system has been entirely changed and now consists of a miniature four-channel analogue tape recorder using a standard compact cassette (Emitape C120) of magnetic recording tape which is sufficient for a continuous 24-hour study. The tape recorder (The Oxford Instrument Co. Ltd., Osney Mead, Oxford OX2 $0 \mathrm{DK}$ ) is completely self-contained and is powered by four small mercury batteries (Mallory RMI), which also supply power to the transducer unit. It is supplied with plug-in input amplifier modules for recording suitable signals such as the electrocardiogram and a carrier module for recording arterial pressure. By the use of a centre zero $1 \mathrm{~mA}$ meter and suitable plug-in monitoring points on the tape recorder it is possible to assess the integrity of the signals in the various channels as they are being fed to the tape. The frequency response of the whole system is flat to $10 \mathrm{~Hz}$. The amplifiers show baseline variation of not more than 2\% FSD over 24 hours, with negligible temperature drift between $20^{\circ}$ and $40^{\circ} \mathrm{C}$. The recorder is small, 10.3 by 8.6 by $3.6 \mathrm{~cm}$, weighs only $300 \mathrm{~g}$, and may be carried with little inconvenience to the subject.

The tape cassettes are replayed on a separate playback deck (The Oxford Instrument Co. Ltd.) at 25 times the recording speed, which allows the replay of a full 24-hour recording in about 60 minutes. During this playback period all or any part of a signal may be fed directly onto an oscilloscope and simultaneously to a (UV) paper recorder so that an additional permanent visual record is obtained. The paper speed may be

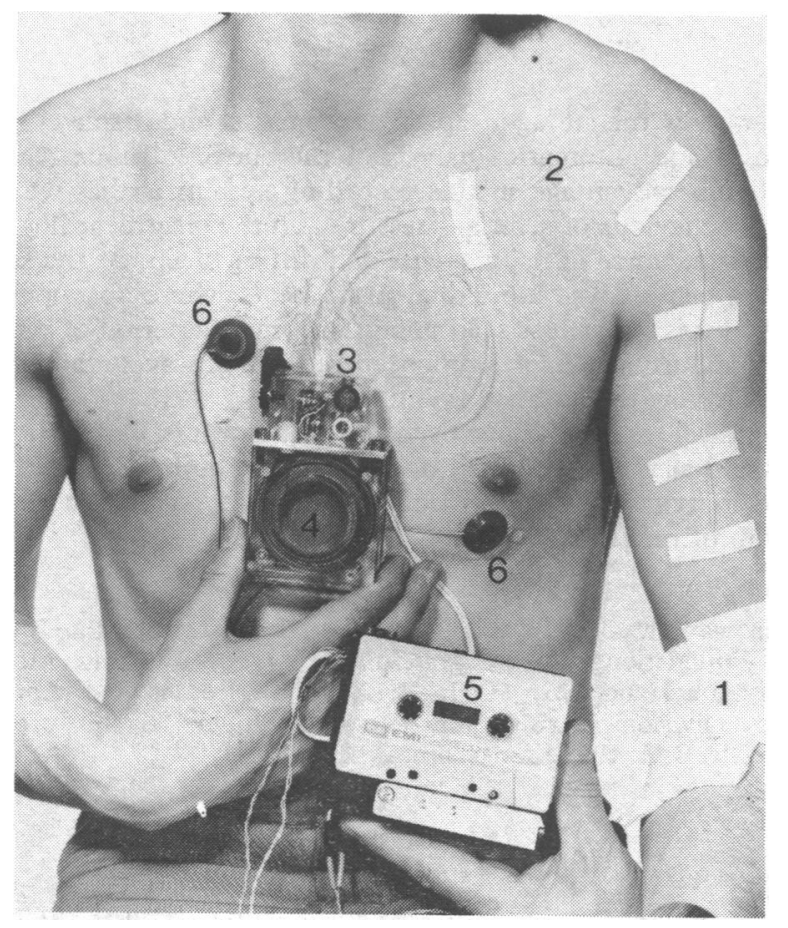

FIG. 1-The apparatus set up on a patient. 1, Intra-arterial catheter. 2, Connecting tubing. 3, Transducer unit. 4, Perfusion chamber. 5, Tape recorder. 6, E.C.G. electrodes. varied at will to display either a single cycle of events in detail or the whole 24-hour study on a few feet of paper (see Fig. 2). The versatility of this system with its electrical recording shows enormous advantages over the photographic records obtained with the earlier apparatus (Bevan et al., 1969), not only in the greater detail available but also in its greater scope for automatic computation.

\section{Methods}

A disposable microcatheter, the Grandjean Arteriocath 3 (Plastimed B.P. 20.95, Saint-Leu-le-Forêt) (length $10 \mathrm{~cm}$, internal diameter $0.9 \mathrm{~mm}$ ), is inserted percutaneously into a brachial artery using the Seldinger technique. The catheter is connected to the perfusion pump by Tefion tubing $0.35 \mathrm{~mm}$ internal diameter and $\mathrm{I} \mathrm{m}$ long. The tubing is anchored to the skin with strapping every $5 \mathrm{~cm}$ to prevent movement artefacts from the tubing as it passes up the arm to the front of the chest, where the perfusion pump, transducer, and tape recorder are carried in a padded harness at heart level (Fig. 1). The transducer is calibrated with a mercury manometer in increments of $50 \mathrm{~mm} \mathrm{Hg}$ giving a stepwise trace, the sensitivity being adjusted to suit the subject under study.

The perfusion pump, transducer, and all connecting tubes are sterilized by perfusing continuously for one hour with Cidex (glutaraldehyde $2 \%$ activated with $0.3 \% \mathrm{NaHCO}_{3}$ ). When the Cidex is removed the whole apparatus is flushed out with several volumes of sterile fluid and refilled with sterile normal saline. At no time can blood enter the connecting tubes or transducer unit because there is constant positive pressure transfusion at a rate limited to $2 \mathrm{ml} / \mathrm{hr}$ by a resistance included in the system, perfusion fluid entering this resistance and the connecting tubes through an acrylic membrane filter, pore size $0.2 \mu \mathrm{m}$ (Acropor AN-200, Gelman Hawksley, Lancing, Sussex). The subject is seen after 12 hours, when his arm and the catheter are inspected, the perfusing reservoir refilled with fresh sterile saline, and a further calibration applied to the transducer.

The electrocardiogram lead system consists of bipolar electrodes (Air-Shields E.C.G. electrodes) placed in one of two positions. When looking for arrhythmias we place one electrode in the midline at the level of the second intercostal space and the other over the cardiac apex. In patients with angina the electrodes are placed over the V5R-V5L positions. Leads are held in place by electrode discs and secured by surgical tape to minimize movement artefact. Positional change does not interfere appreciably with the interpretation of arrhythmias, but S-T segment changes must be interpreted with more caution.

Finally, the subject carries a diary in which he records the timing of important events such as onset of pain in angina, and he indicates these simultaneously on the tape by an electrical pulse initiated by a microswitch.

\section{Subjects}

Records were made in 25 subjects, all of whom volunteered for the investigation, the nature of which was explained to them. Seventeen had hypertension and the remainder suffered from angina pectoris.

\section{Results}

The detailed analysis of these records will form the basis of a further communication, but the type of record obtained with this system is shown in Figs. 2-6.

\section{Discussion}

The system of recording used and the electrical signals which represent the arterial pressure, electrocardiogram, and event 


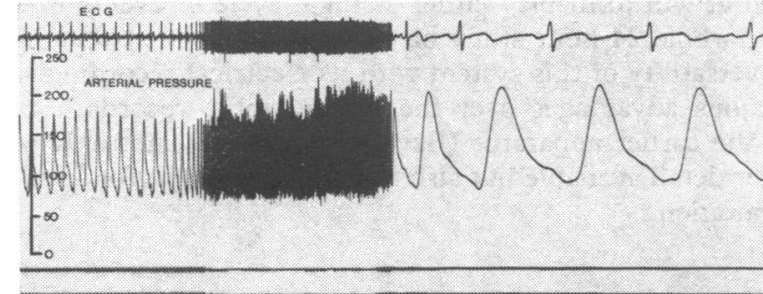

FIG. 2-Versatility of playback unit. Individual pulse beats can easily be analysed, while blood pressure over longer periods is best appreciated from slower speed. Record is calibrated in $\mathrm{mm} \mathrm{Hg}$ in this Fig. and in Figs. 3-6.

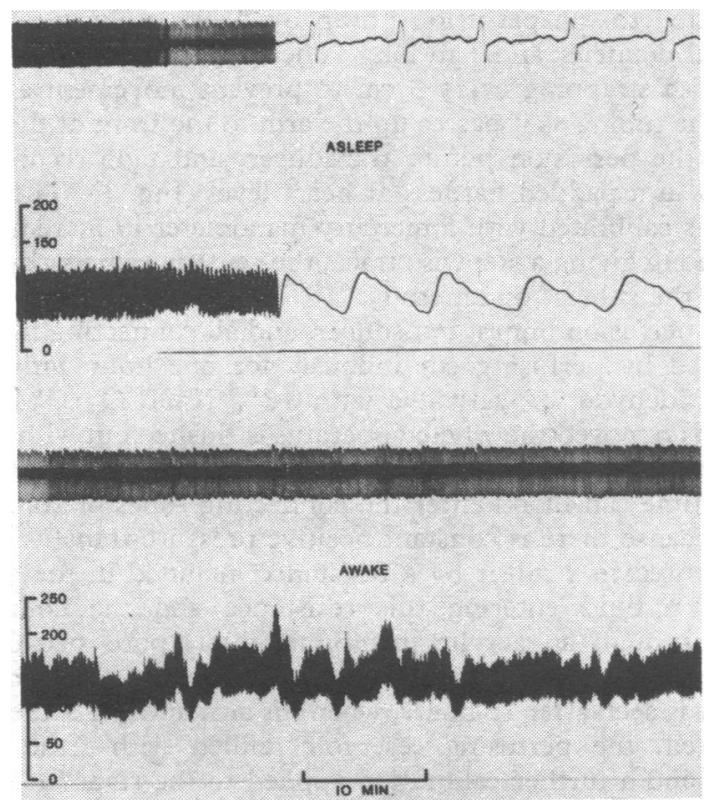

FIG. 3-Records obtained from 54-year-old hypertensive man. During sleep his blood pressure was lower and more stable than during waking hours.

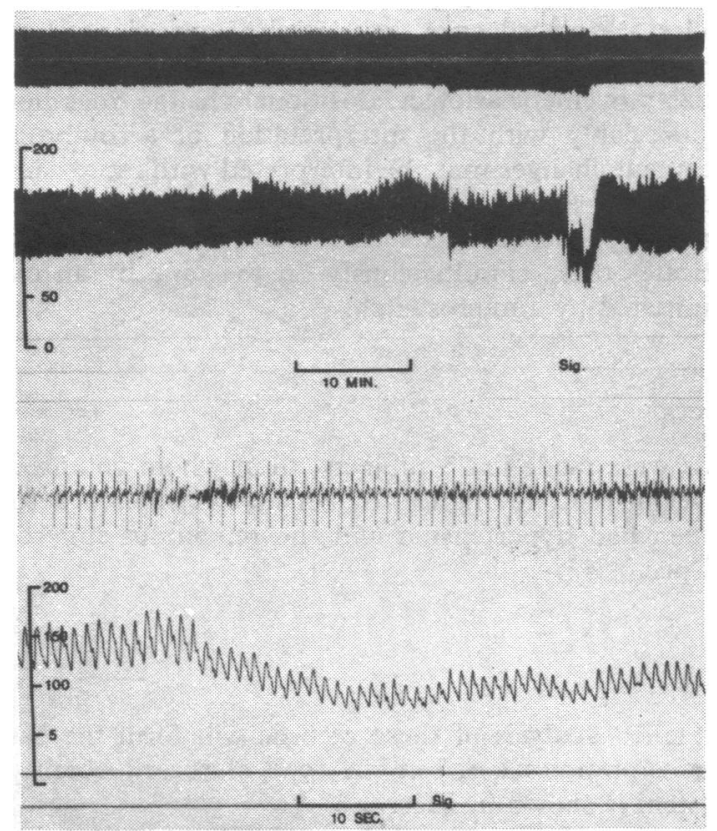

FIG. 4-Records from 37-year-old woman with essential hypertension on treatment with bethanidine. Record obtained when patient awakened to go to the lavatory. Signal indicates when she got out of bed and is followed by hypotensive episode. On the faster playout of this episode it is obvious that postural hypotension had already occurred when she pressed her signal marker. Note increased muscle potentials in E.C.G. record during time that she was presumably rising from her bed.

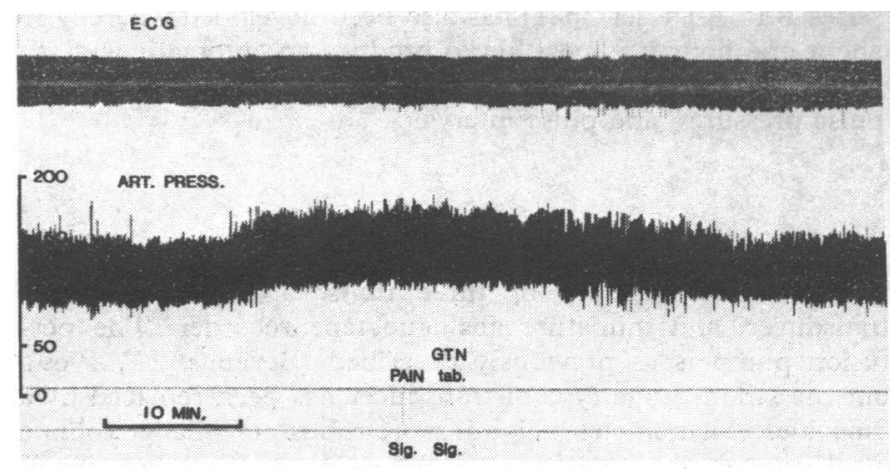

FIG. 5-Record from 62-year-old man with severe angina pectoris. The first signal indicates severe pain, the second was time when he took glyceryl trinitrate (GTN). Note that his blood pressure had already risen when he experienced the worst of his pain, and also note the lack of any pronounced hypotension after the trinitrate.

ECC

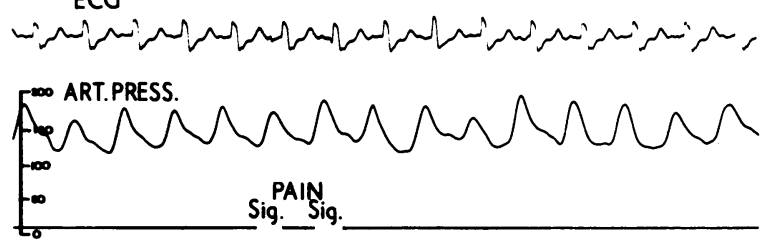

ECC

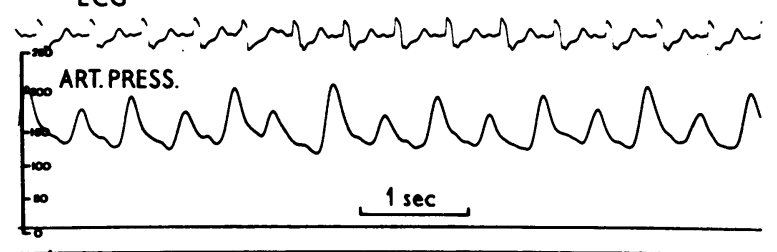

FIG. 6-Beat-to-beat analysis of part of Fig. 5. Signals indicate pain (at this fast speed the signal is represented by two spikes). Note in lower record (1) pulsus alternans occurring at height of his pain, and (2) depression of $S-T$ segment of E.C.G.

marker allow the storage, repeated extraction and display of the readings, and automatic analysis of the entire 24-hour record. An obvious advantage in this recording system is that we can see the behaviour of arterial pressure and the electrocardiogram during the course of daily events and during sleep. At the same time we can analyse individual pulse beats where appropriate. This point is well illustrated in Fig. 6, where a period of pulsus alternans during severe angina occurred which was not apparent from the slow trace of the event.

Technical problems have been few, and our initial experiences indicate that the method is safe and causes minimal discomfort to the individual and does not interfere appreciably with his freedom of movement or sleep.

This work was supported in part by a grant from the British Heart Foundation. We are grateful to Mr. D. Williams, Mr. F. D. Seymour, and Mr. H. J. Reid, of Electronics and Applied Physics Division, Harwell, for help and support in this project, and to Mr. B. A. Stone for technical help.

\section{References}

Bevan, A. T., Honour, A. J., and Stott, F. D. (1969). Clinical Science, 36, 329 .

Richardson, D. W., Honour, A. J., Fenton, G. W., Stott, F. D., and Pickering, G. W. (1964). Clinical Science, 26, 445. 